\title{
An observational study examining the effects of a surgically induced inflammatory response on the distribution of morphine and its metabolites into cerebrospinal fluid Les effets d'une réaction inflammatoire induite par chirurgie sur la distribution de morphine et de ses métabolites dans le liquide céphalorachidien : une étude observationnelle
}

\author{
Yan Wang, MSc • Kerry B. Goralski, PhD • Derek J. Roberts, MD, PhD • \\ Kathryn Landry, BSc • Mark E. Issa, MSc • Lekha Sleno, PhD • Lisa C. Julien, BScN • \\ Jeremy Wood, MD • Richard I. Hall, MD $\mathbb{D}$ \\ Received: 13 December 2016/Revised: 25 May 2017 / Accepted: 5 July 2017/Published online: 14 July 2017 \\ (C) Canadian Anesthesiologists' Society 2017
}

\begin{abstract}
Purpose Morphine is administered intravenously for pain management in the perioperative period. The effect of the inflammatory response to surgery on morphine distribution across the blood-brain barrier (BBB) in humans was investigated. We hypothesized that a graded surgically induced, systemic inflammatory response alters cerebrospinal fluid (CSF) levels of morphine, morphine3-glucuronide (M3G), and morphine-6-glucuronide (M6G) through a temporary reduction in BBB drug efflux transporter function.
\end{abstract}

This article is accompanied by an editorial. Please see Can J Anesth 2017; 64: this issue.

Electronic supplementary material The online version of this article (doi:10.1007/s12630-017-0933-x) contains supplementary material, which is available to authorized users.

Y. Wang, MSc · K. B. Goralski, PhD · K. Landry, BSc .

M. E. Issa, MSc

College of Pharmacy, Faculty of Health Professions, Dalhousie

University, Halifax, NS, Canada

K. B. Goralski, PhD · R. I. Hall, MD

Department of Pharmacology, Faculty of Medicine, Dalhousie University, Halifax, NS, Canada

D. J. Roberts, MD, PhD

Departments of Surgery, University of Calgary, Calgary, AB, Canada

L. Sleno, $\mathrm{PhD}$

Department of Chemistry, Université du Québec à Montréal,

Montréal, QC, Canada
Methods We conducted a prospective pharmacokinetic study of the plasma and CSF distribution of the $P$-glycoprotein (PGP) substrate morphine in 33 patients undergoing open thoracic $(n=18)$ or endovascular $(n=15)$ aortic aneurysm repair. Morphine was administered with induction of anesthesia and in the intensive care unit. Plasma and CSF concentrations of interleukin (IL)-6, morphine, M3G, M6G, and albumin were measured prior to surgery (baseline), during surgery, and postoperatively every six hours until removal of the CSF drain. The area under the curve (AUC) was determined for plasma and CSF IL-6, morphine, M3G, and M6G concentrations vs time. The primary endpoint measures were the correlations between the morphine, $M 6 G$, and M3G AUC CSF/plasma ratios and systemic inflammation as quantified by the time-normalized IL-6 exposure, which was calculated for each individual by

L. C. Julien, BScN · R. I. Hall, MD ( $\varangle)$

Department of Critical Care Medicine, Queen Elizabeth II Health Sciences Centre, Capital District Health Authority,

Halifax, NS, Canada

e-mail: rihall@dal.ca

J. Wood, MD

Division of Cardiothoracic Surgery, Capital District Health Authority, Dalhousie University and Queen Elizabeth II Health Sciences Centre, 1796 Summer St., Halifax, NS B3H 3A7, Canada

\section{R. I. Hall, MD}

Departments of Critical Care Medicine, Pharmacology and Anesthesia, Pain Management and Perioperative Medicine, Faculty of Medicine, Dalhousie University, Halifax, NS, Canada 
dividing the total exposure (AUC) by time ( $t$ ). A Bonferroni corrected $P<0.017$ indicated a significant correlation.

Results Plasma and CSF IL-6 concentrations increased postoperatively. The median [interquartile range] IL-6 exposures were significantly higher in the open vs endovascular surgical group for plasma (105 [40-256] $\mathrm{pg} \cdot \mathrm{mL} \mathrm{L}^{-1}$ vs 29 [16-70] $\mathrm{pg} \cdot \mathrm{mL} \mathrm{L}^{-1}$, respectively; $P=0.013$ ) and CSF (79 [26-133] $\mathrm{pg} \cdot \mathrm{mL}^{-1}$ vs 16 [9-80] $\mathrm{pg} \cdot \mathrm{mL}^{-1}$, respectively; $P=0.013)$. For the primary endpoint, the plasma IL-6 AUC/t did not correlate with the CSF accumulation of morphine $(r=-0.009 ; P=0.96)$ or M3G ( $r=0.37 ; P=0.04)$ when corrected for surgical procedure, age, and sex. There were insufficient data on CSF concentration to complete the primary analysis for $M 6 G$.

Conclusion Morphine distribution into the CSF was not significantly altered in patients undergoing thoracic aortic aneurysm repair. This suggests that BBB PGP function may not be affected by the perioperative inflammatory response.

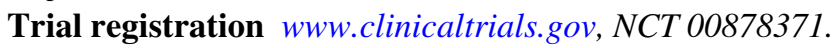
Registered 7 April 2009.

\section{Résumé}

Objectif La morphine administrée par voie intraveineuse est utilisée pour prendre en charge la douleur en période périopératoire. Nous avons examiné l'effet de la réaction inflammatoire à la chirurgie sur la distribution de morphine à travers la barrière hémato-encéphalique (BHE) chez l'humain. Nous avons émis l'hypothèse qu'une réaction inflammatoire systémique notée et induite par la chirurgie altérait les taux de morphine, de morphine-3-glucuronide (M3G) et de morphine6-glucuronide (M6G) dans le liquide céphalorachidien $(L C R)$ en réduisant temporairement la fonction de transporteur efflux de la BHE.

Méthode Nous avons réalisé une étude pharmacocinétique prospective de la distribution dans le plasma et le LCR des substrats de morphine de la P-glycoprotéine (PGP) chez 33 patients subissant une réparation d'anévrisme aortique thoracique ouverte $(n=18)$ ou endovasculaire $(n=15)$. La morphine a été administrée à l'induction de l'anesthésie puis à l'unité de soins intensifs. Les concentrations dans le plasma et le LCR d'interleukine (IL)-6, de morphine, de M3G, de M6G et d'albumine ont été mesurées avant la chirurgie (mesures de base), pendant la chirurgie et en période postopératoire toutes les six heures jusqu'au retrait du drain de LCR. La surface sous la courbe (SSC) a été déterminée pour les concentrations d'IL-6, de morphine, de M3G et de M6G dans le plasma et le LCR vs le temps. Les critères d'évaluation principaux étaient les corrélations entre les taux de SSC dans le LCR/plasma de morphine, de M6G et de M3G et l'inflammation systémique telle que quantifiée par la quantité d'IL-6 normalisée dans le temps, qui a été calculée pour chaque personne en divisant l'exposition totale (SSC) par le temps ( $t$ ). Une correction de Bonferroni de $P<0,017$ indiquait une corrélation significative.

Résultats Les concentrations dans le plasma et le LCR d'IL-6 ont augmenté en période postopératoire. Les expositions médianes [écart interquartile] à l'IL-6 étaient significativement plus élevées dans le groupe chirurgie ouverte vs chirurgie endovasculaire (105 [40-256] $\mathrm{pg} \cdot \mathrm{mL}^{-1}$ vs 29 [16-70] $\mathrm{pg} \cdot \mathrm{mL}^{-1}$, respectivement; $P=0,013)$ et dans le LCR vs le plasma (79 [26-133] $\mathrm{pg} \cdot \mathrm{mL}^{-1}$ vs 16 [9-80] $\mathrm{pg} \cdot \mathrm{mL}^{-1}$, respectivement; $P=0,013)$. En ce qui a trait au critère d'évaluation principal, le taux SSC/t d'IL-6 dans le plasma n'était pas corrélé à l'accumulation de morphine $(r=-0,009$; $P=0,96)$ ou de M3G ( $r=0,37 ; P=0,04)$ dans le LCR lorsqu'il était corrigé pour tenir compte de l'intervention chirurgicale, de l'âge et du sexe. Les données recueillies étaient insuffisantes concernant la concentration dans le LCR pour finaliser l'analyse primaire pour le M6G.

Conclusion La distribution de morphine dans le LCR n'a pas été significativement altérée chez les patients subissant une réparation d'anévrisme thoracique. Cela suggère que la fonction de barrière hémato-encéphalique de la PGP pourrait ne pas être affectée par une réaction inflammatoire périopératoire.

Enregistrement de l'étude $w w w$.clinicaltrials.gov, NCT 00878371. Enregistrée le 7 avril 2009.

Morphine is frequently administered in the perioperative period for pain management. Surgically induced inflammation may alter drug pharmacokinetics, ${ }^{1}$ and altered function of protective blood-brain barrier (BBB) drug efflux transporters, including P-glycoprotein (PGP) and multidrug resistance-associated proteins (MRPs), may contribute to these observations. ${ }^{2-4}$ Cellular and animal studies provide evidence that human and rodent PGP transports morphine. ${ }^{5,6}$ Furthermore, experimental evidence suggests that a reduction in BBB PGP function enhances brain morphine accumulation and antinociceptive effects $^{7-9}$ and clinical response. ${ }^{10-12}$ Therefore, if morphine distribution across the BBB is enhanced by inflammationmediated inhibition of PGP, this could be manifest as increasing analgesic effect for the same stable dosing level over time with the potential for toxicity.

Morphine-6-glucuronide (M6G) and morphine3-glucuronide (M3G) are the two primary metabolites of morphine produced in humans. M6G shows twofold higher affinity for the $\mu$-opioid receptor and contributes to 
analgesia following morphine administration. While M3G has very weak binding affinity for the $\mu$-opioid receptor and no analgesic activity, antagonistic or neuroexcitatory effects have been reported. ${ }^{13-15}$ Both $\mathrm{M} 3 \mathrm{G}$ and M6G are transported by MRP transporters expressed at the BBB. ${ }^{16,17}$ Thus, if inflammation-induced alteration in BBB MRP function occurs, this could be manifest as central nervous system (CNS) disturbances (frequently seen clinically and possibly attributable to M3G toxicity) and/or increased analgesic effect (possibly attributable to the effects of the metabolite M6G) with its possible attendant toxicity.

Animal and cell-based studies have shown that the expression and/or function of protective BBB drug efflux transporters, including PGP and MRP, are differently altered under acute inflammatory conditions. ${ }^{4,16,18-24}$ Most studies report reductions in BBB drug efflux transporter function during inflammation, with a resultant accumulation of drug efflux transporter substrates in the CNS. Nevertheless, these studies are limited by interspecies differences and the low expression of BBB tight junctions and drug transporters in human in vitro cell models. $^{25,26}$ Therefore, additional human translational studies are needed to confirm or refute the conclusions based on animal and in vitro studies. ${ }^{4}$

We have previously shown that, while the cerebrospinal fluid (CSF) uptake of morphine remained relatively unchanged after an acute neuroinflammatory response, there was a large associated increase in the uptake of M3G/ M6G without a concomitant change in a marker of passive BBB function (i.e, albumin). ${ }^{2}$ These data raise concerns that acute CNS inflammatory responses may alter BBB drug handling in humans. Nevertheless, there are limited clinical data examining the association between a systemic inflammatory response and BBB PGP activity in humans. Thus, we conducted a prospective pharmacokinetic study to test the hypothesis that a graded surgically induced, peripheral systemic inflammatory response alters CSF levels of morphine, M3G, and M6G through a temporary reduction in BBB drug efflux transporter function that would be evidenced by a positive correlation between the morphine, M6G, and M3G area under the curve (AUC) $\mathrm{CSF} /$ plasma ratios and systemic inflammation as quantified by time-normalized plasma IL-6 exposure.

\section{Methods}

\section{Trial design}

The Capital District Health Authority Research Ethics Board approved this prospective cohort study in May 2009 (ethics ID: CDHA -RS/2010-004). The study conformed to the STROBE guideline for reporting observational studies. ${ }^{27}$ The study principal investigators (K.B.G., R.I.H.) had complete access to the study data.

Study participants and interventions

From May 2009 to February 2013, consecutive adult patients presenting to the Queen Elizabeth II Health Sciences Centre in Halifax, Nova Scotia, Canada for elective repair of a descending thoracic aortic aneurysm were screened for study eligibility. We included adults undergoing elective endovascular or open surgical repair of a thoracic aortic aneurysm, with or without cardiopulmonary bypass (CPB), who required insertion of a lumbar CSF drain and provided written informed consent. The patients were not blinded to the study allocation or procedures. We excluded patients who were sensitive or allergic to morphine or unable to have a lumbar CSF drain placed.

Prior to induction of anesthesia, a peripheral arterial catheter and a lumbar CSF drain were placed in each patient. These remained in situ during the surgical procedure. Prior to administration of morphine, CSF (5-15 mL) was collected into a dedicated reservoir and blood $(5 \mathrm{~mL})$ was collected into a glass tube containing sodium citrate. Patients were then administered morphine 5-10 mg at induction of anesthesia. Subsequently, upon arriving at the intensive care unit (ICU), patients were given (as needed for analgesia) morphine $0.5-4.0 \mathrm{mg} i v$ boluses or a continuous intravenous morphine infusion of $1-2 \mathrm{mg} \cdot \mathrm{hr}^{-1}$. Cerebrospinal fluid $(5-15 \mathrm{~mL})$ and blood samples $(5 \mathrm{~mL})$ were obtained from all patients immediately prior to incision, at wound closure, and then every six hours until the lumbar CSF drain was removed for clinical reasons. To account for the additional role that heparin and CPB might play in affecting cytokine levels, CSF and blood samples were obtained from patients undergoing open surgery with $\mathrm{CPB}$ immediately prior to initiation of $\mathrm{CPB}$ and immediately following return of native circulation postCPB. The CPB priming solution consisted of Normosol, and glucocorticoids were not administered. Albumin was not administered intraoperatively or postoperatively to any patient. The course of a patient's care was unaltered in the operating room or ICU other than to encourage the use of morphine as the primary narcotic analgesic agent while in the ICU. Some individuals received other supplemental narcotic analgesics-i.e., fentanyl $(n=9)$, hydromorphone $(n=10)$, and/or meperidine $(n=4)$. Following collection, CSF and blood samples were kept on ice for 1-12 hr. Blood samples were centrifuged for ten minutes at $1,100 \mathrm{~g}$ to prepare plasma. The CSF and plasma samples were divided into working aliquots and stored at $-70^{\circ} \mathrm{C}$ prior to analysis. 
Cytokines and albumin determination

A Q-Plex ${ }^{\mathrm{TM}}$ human cytokine inflammation (9-plex) ELISA kit (Quansys Biosciences, Logan, UT, USA) and LI-COR ${ }^{\circledR}$ Odyssey infrared imaging system were used to determine concentrations of interleukin (IL) $-1 \alpha,-1 \beta,-2,-4,-6$, -10 , and -12 ; interferon gamma $\left(\operatorname{IFN}_{\gamma}\right)$; and tumour necrosis factor (TNF) in plasma and CSF samples according to the manufacturer's protocol (see Electronic Supplementary Materials [ESM], methods). Sample cytokine concentrations below the lowest detectable standard cytokine concentrations were assumed to be zero. Albumin concentrations $\left(\mathrm{g} \cdot \mathrm{L}^{-1}\right)$ in plasma and CSF samples were determined using a bromocresol green-based assay (QuantiChrom $^{\mathrm{TM}}$, BioAssay Systems, Hayward, CA, USA) according to manufacturer's directions (see ESM, methods).

Morphine and metabolite quantification

Methods to determine total concentrations of morphine, $\mathrm{M} 3 \mathrm{G}$, and $\mathrm{M} 6 \mathrm{G}$ in plasma and in CSF samples were validated and described in detail in a previously published study (see ESM, methods). ${ }^{2}$ Samples with analyte concentrations that fell below the lower limit of quantitation $\left(1 \mathrm{ng} \cdot \mathrm{mL}^{-1}\right.$ for plasma and $0.5 \mathrm{ng} \cdot \mathrm{mL}^{-1}$ for $\mathrm{CSF}$ ) were considered to be zero.

\section{Data analysis}

The intensity of inflammatory response in CSF and peripheral blood was estimated by comparing the peak cytokine concentrations $\left(\mathrm{C}_{\max }\right)$ after surgery with the baseline concentrations $\left(\mathrm{C}_{0}\right)$ just prior to surgery. The AUC for plasma and CSF cytokines, morphine, M3G, and M6G was used as a measure of the "total exposure" of the body and the brain to these substances as previously described (see ESM, methods). ${ }^{2}$ The AUCs were calculated using PK Solutions 2.0 (Summit Research Services, Montrose, CO, USA). The morphine and M3G and M6G AUC values (ng $\cdot \mathrm{mL}^{-1} \cdot \mathrm{hr}^{-1}$ ) were normalized to the individual total morphine dose $(\mathrm{mg})$ to account for differences in morphine dosing between patients. The plasma morphine elimination rate constant $\mathrm{k}_{\mathrm{el}}$ and elimination half-life $\left(\mathrm{t}_{1 / 2}\right)\left(0.693 / \mathrm{k}_{\mathrm{el}}\right)$ were determined by least-squares linear regression of the elimination phases (defined by a minimum of three points) of the $\log _{10^{-}}$ transformed plasma morphine concentration $v s$ time curves. For each serial time point, the ratio of metabolites to morphine-i.e., M3G/M and M6G/M in plasma and $\mathrm{M} 3 \mathrm{G} / \mathrm{M}$ in CSF, was also calculated in order to assess the effect of the surgical procedure on the metabolism and elimination of morphine, M3G, and M6G. To assess BBB passive permeability of albumin, the CSF/plasma albumin ratio was determined for each serial time point using the formula CSF albumin $\left(\mathrm{g} \cdot \mathrm{L}^{-1}\right)$. 1,000 /plasma albumin $\left(\mathrm{g} \cdot \mathrm{L}^{-1}\right) .^{28}$ Skewed continuous data were summarized using median [interquartile range (IQR)] and presented graphically as line plots or Tukey box and whisker plots.

\section{Statistical analysis}

The primary endpoint measures were the correlations between morphine, M3G, and M6G AUC CSF/plasma ratios and systemic inflammation as quantified by the timenormalized IL-6 exposure. This was calculated for each individual by dividing the AUC by time (t). Interleukin- 6 was chosen as the primary inflammation variable. ${ }^{29}$ Our initial analysis of plasma and CSF samples determined that the CSF M6G concentrations typically fell below the lower limit of assay quantification. Thus, there were insufficient concentration data available to complete the primary analysis for M6G. A correlation between patients was performed as per published methodology. ${ }^{30}$ Briefly, each measured IL-6 exposure was transformed using $\log _{10}$, as the variable was not normally distributed as determined by the Shapiro-Wilk test. The mean $\log _{10}$-transformed IL-6 exposures and the raw morphine and M3G AUC $\mathrm{CSF} /$ plasma ratios were calculated for each subject and weighted based on the number of paired measurements for each subject. A Pearson's correlation of the $\log _{10^{-}}$ transformed plasma IL-6 exposures $v s$ the morphine and M3G AUC CSF/plasma ratios was performed with and without correction for age, sex, and type of surgery. A $P$ value $<0.017$ (two-sided with Bonferroni correction for multiple comparisons) was used as the statistical cutoff to reject the null hypothesis (i.e., no correlation between plasma IL-6 exposures and the morphine, M3G, M6G AUC $\mathrm{CSF} /$ plasma ratios). Based on our previous work, ${ }^{2}$ we judged for our primary endpoint measure that a difference from baseline in the correlation between morphine and/or M3G and M6G AUC CSF/plasma ratios and the average plasma IL-6 exposure from 0 (i.e., no relationship) to 0.70 would represent an important statistical and clinical relationship and would satisfy our hypothesis. An overall sample size of 19 achieves $83 \%$ power to detect a difference of -0.70 between the null hypothesis correlation of 0.00 and the alternative hypothesis correlation of 0.70 using a two-sided hypothesis test with a significance level of $P \leq 0.01$. To allow for subject dropout (e.g., insufficient CSF or accidental catheter removal), we aimed to enroll a minimum of 30 patients.

The secondary endpoint measures included the correlation between the morphine, M3G, and M6G CSF/plasma ratios and plasma IL-10 and CSF IL-6. This was developed as a post hoc effort based on the observed 
cytokine responses. The correlations were performed as described for the primary endpoint. We also sought to determine if the type of surgical procedure (i.e., open $v s$ endovascular) differentially affected the inflammatory response and morphine pharmacokinetics. For this analysis, patients were stratified into two groups according to the anticipated magnitude of the inflammatory response: 1) anticipated low to moderate inflammatory response (endovascular group) and 2) those with anticipated high inflammatory response (open thoracotomy with or without CPB [open group]). A Friedman non-parametric analysis of variance with Bonferroni correction for multiple comparisons was used for within-group comparisons of cytokines and albumin concentrations over time. A non-parametric Mann-Whitney Student's $t$ test was used for comparisons of measured variables between the endovascular and the open groups at defined time points. A $P$ value $<0.05$ indicated a significant difference in the measured variables. For all Mann-Whitney tests, the Hodges-Lehman estimate of the median difference between group medians and the corresponding $95 \%$ confidence interval (CI) were determined. In all cases, hypothesis testing was twotailed. Statistical analysis was performed using IBM SPSS ${ }^{\circledR}$ Statistics version 23 (IBM Corporation, Armonk, NY, USA), with the exception of the Hodges-Lehman estimate and corresponding 95\% CI, which were determined using GraphPad Prism version 6 (GraphPad Software, La Jolla, CA, USA).

\section{Results}

Patient demographics, morphine dosing, clinical outcomes, and concomitant drugs

Thirty-six patients were recruited into the study. Two patients were excluded after a review of their chart revealed that they were administered codeine or morphine prior to collection of the baseline (time 0) sample. A third subject was excluded because of insufficient blood and CSF samples for analysis. Eighteen $(55 \%)$ of the 33 remaining patients underwent an open surgical procedure, 17 of whom received CPB.

Table 1 depicts the study patient characteristics stratified by open $v s$ endovascular surgical repair. The median age of patients in the open group was significantly lower (eight years) than that of the endovascular group. In the open $v s$ the endovascular group, the median duration of surgery was longer (by $6.1 \mathrm{hr}$ ), the median cumulative morphine dose was higher (by $7 \mathrm{mg}$ ), and the median duration of morphine administration was longer (by $14 \mathrm{hr}$ ). The average morphine-dosing rate $\left(\mathrm{mg}_{\mathrm{hr}}{ }^{-1}\right)$ and ICU duration were not different between the groups. Two

Table 1 Summary of patients' characteristics

\begin{tabular}{|c|c|c|c|c|c|}
\hline & Total & $\begin{array}{l}\text { Endovascular } \\
\text { Surgery }\end{array}$ & $\begin{array}{l}\text { Open surgery } \\
( \pm \mathrm{CPB})\end{array}$ & $P$ value $^{\mathrm{a}}$ & $\begin{array}{l}\text { Difference between } \\
\text { medians and }(95 \% \mathrm{CI}) \\
\text { of difference }^{\mathrm{b}}\end{array}$ \\
\hline Sample Size & 33 & 15 & 18 & NA & \\
\hline Age $(y r)$ & $74[64-78]$ & $77[71-84]$ & $69[54-76]$ & $P=0.01$ & $-9.0(-19.0$ to -2.0$)$ \\
\hline $\operatorname{Sex}(M / F)$ & $23 / 10$ & $10 / 5$ & $13 / 5$ & NA & NA \\
\hline Height $(\mathrm{cm})$ & $173[162-180]$ & $168[160-180]$ & $174[164-181]$ & $P=0.38$ & $5.0(-5.0$ to 13$)$ \\
\hline Weight (kg) & $76[68-91]$ & $76[66-91]$ & $76[68-91]$ & $P=0.73$ & $1.3(-9.4$ to 11.8$)$ \\
\hline Surgery Duration (hr) & $4.8[1.7-7.7]$ & $1.4[1.1-3.7]$ & $7.5[4.7-8.4]$ & $P<0.001$ & $4.6(2.8$ to 6.5$)$ \\
\hline Total Morphine Dose (mg) & $18[14-26]$ & $15[12-24]$ & $22[17-36]$ & $P=0.008$ & $7.0(2.0$ to 15$)$ \\
\hline Morphine Duration $(\mathrm{hr})^{\mathrm{c}}$ & $17[9-34]$ & $10[6-20]$ & $24[13-42]$ & $P=0.007$ & $12.9(3.5$ to 25.8$)$ \\
\hline Morphine dosing rate ${ }^{\mathrm{c}}\left(\mathrm{mg} \cdot \mathrm{hr}^{-1}\right)$ & $1.1[0.8-1.5]$ & $1.4[0.8-1.6]$ & $1.1[0.7-1.4]$ & $P=0.26$ & $-0.18(-0.60$ to 0.25$)$ \\
\hline ICU Duration (hr) & $35[20-84]$ & $24[18-75]$ & $45[20-120]$ & $P=0.40$ & $8.75(-11.8$ to 44.3$)$ \\
\hline Subjects receiving potential PGP inhibitors & $n=9$ & $n=5$ & $n=4$ & NA & NA \\
\hline Amiodarone & 6 & 3 & 3 & & \\
\hline Nifedipine & 1 & 1 & 0 & & \\
\hline Pantoprazole & 4 & 2 & 2 & & \\
\hline
\end{tabular}

Data are shown as median [interquartile range]. ${ }^{\mathrm{a}} \mathrm{P}<0.05$ denotes a statistically significant difference between ranks for each parameter between the open surgery $v s$ the endovascular surgery groups, non-parametric Mann-Whitney test. NA $=$ not applicable. ${ }^{\mathrm{b}}$ The reported median difference is the Hodges-Lehman difference in the medians of the open $v s$ endovascular groups. The corresponding 95\% confidence intervals (CIs) of the median differences are shown in brackets. ${ }^{\mathrm{c}}$ Two subjects received a single bolus dose of morphine; thus, the duration and the dosing rate for these subjects were not determined. $\mathrm{CPB}=$ cardiopulmonary bypass; ICU = intensive care unit; PGP = P-glycoprotein 

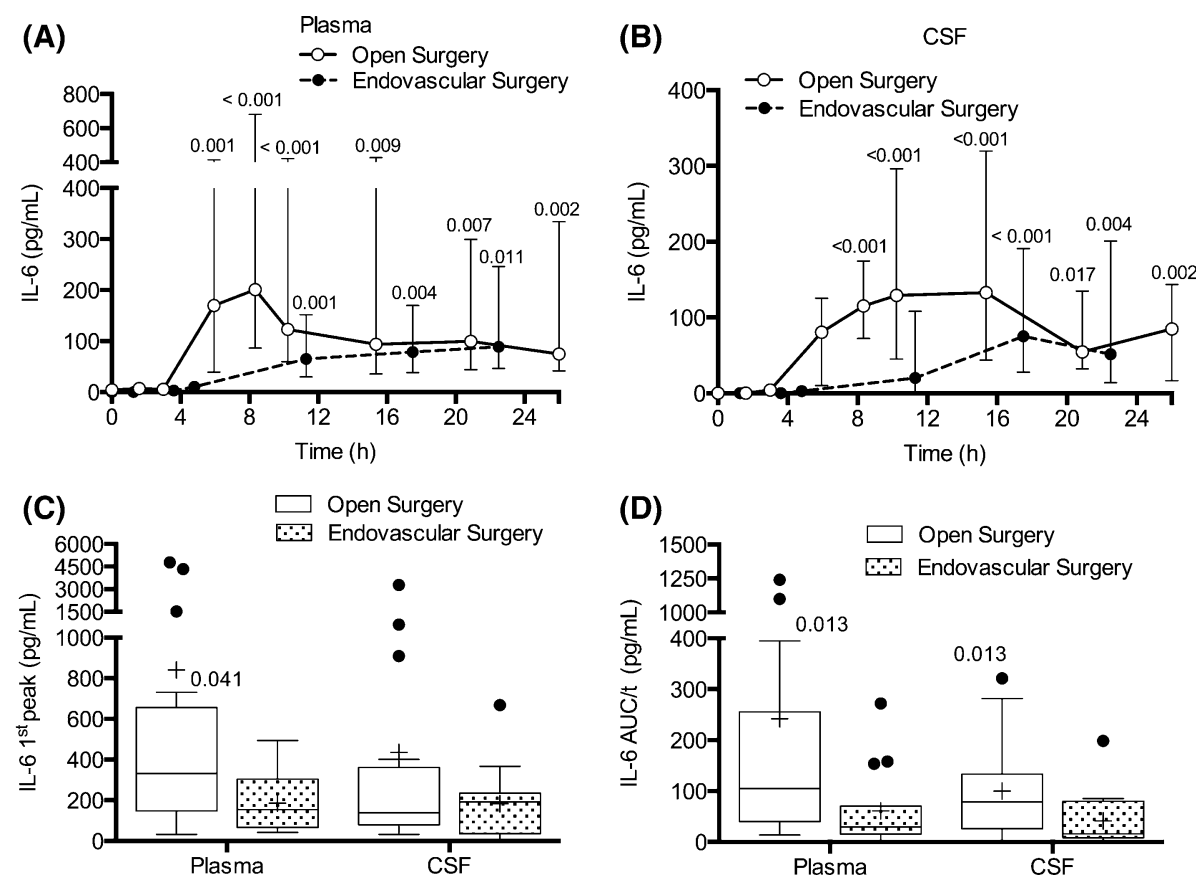

Fig. 1 The effect of open and endovascular aortic aneurysm surgery on plasma and cerebrospinal fluid (CSF) interleukin-6 (IL-6) concentrations. Plasma (A) and CSF (B) IL-6 concentrations were measured in patients undergoing open surgical procedures with or without cardiopulmonary bypass or in patients undergoing endovascular surgical procedures. The symbols and error bars depict the median [interquartile range (IQR)] raw concentrations $v s$ average sampling times. The $P$ values indicate a significant difference compared with the within-group baseline control value at time 0 , Friedman non-parametric analysis of variance with Bonferroni

participants died as a result of postoperative complications. Nine patients (endovascular $n=5$; open $n=4$ ) received concomitant PGP inhibitors (e.g., amiodarone, nifedipine or pantoprazole) while in the ICU.

Systemic and CNS inflammatory responses and albumin distribution

A significant increase in the measured plasma and CSF IL6 concentrations occurred in both the open and endovascular aortic surgery groups relative to the time 0 baseline (Fig. 1A, B). The first peak plasma IL-6 concentration and the median plasma and CSF timenormalized IL-6 exposures were significantly higher in the open surgery $v s$ the endovascular surgery group (Fig. 1C, D). The median differences between the open and endovascular groups were: $178 \mathrm{pg} \cdot \mathrm{mL}^{-1}(95 \% \mathrm{CI}, 31$ to 433) and $47 \mathrm{pg} \cdot \mathrm{mL}^{-1}(95 \% \mathrm{CI},-63$ to 191$)$ for peak plasma and CSF IL-6, respectively and $50 \mathrm{pg} \cdot \mathrm{mL}^{-1}(95 \%$ CI, 12 to 171) and $42 \mathrm{pg} \cdot \mathrm{mL}^{-1}$ (95\% CI, 5.5 to 83 ) for the respective time-normalized plasma and CSF IL-6 exposures. Plasma IL-10 increased significantly in the

correction for multiple comparisons. Tukey box plots show the median first peak IL-6 concentrations (C) and time-normalized IL-6 area under the curves (D) determined from the plasma and CSF concentration $v s$ time profiles. Outliers beyond $1.5 \times \mathrm{IQR}$ are identified by the filled circles $(\bullet)$, and the mean values are indicated by the $(+)$ symbol. The $P$ values indicate a significant difference compared with the endovascular surgery group, Mann-Whitney nonparametric Student's $t$ test. The data analysis in A and B included samples up to an average time of $26 \mathrm{hr}$ (x-axis) due to limited available samples beyond that time point

open surgical group only (Fig. 2A). This was reflected by a significantly higher IL-10 $1^{\text {st }}$ peak and time-normalized exposure in the plasma of open surgical vs endovascular surgical patients (Fig. 2B, C). The median differences between the open and endovascular groups were 413 $\mathrm{pg} \cdot \mathrm{mL}^{-1}(95 \% \mathrm{CI}, 149$ to 802$)$ and $151 \mathrm{pg} \cdot \mathrm{mL}^{-1}(95 \% \mathrm{CI}$, 68 to 258) for peak plasma IL-10 and time-normalized plasma IL-10 exposure, respectively. Cerebrospinal fluid IL-10 was undetectable in the majority of samples and was excluded from further analysis. Plasma and CSF levels of $\mathrm{IL}-1 \alpha, \mathrm{IL}-1 \beta,-2,-4$, and -12 , IFN $\gamma$, and TNF displayed measurable concentrations only in a minority of patient samples. Consistent postoperative increases in these cytokines were not observed (ESM, Fig. 1), and therefore, these cytokines were not analyzed further.

The open and endovascular aortic surgical patients displayed a temporary decrease in the plasma albumin concentration in the post-surgical period compared with baseline (Fig. 3A). Cerebrospinal fluid albumin did not significantly increase relative to baseline in either group. This resulted in a marginally higher median CSF/plasma albumin exposure in the open $v s$ the endovascular surgical 


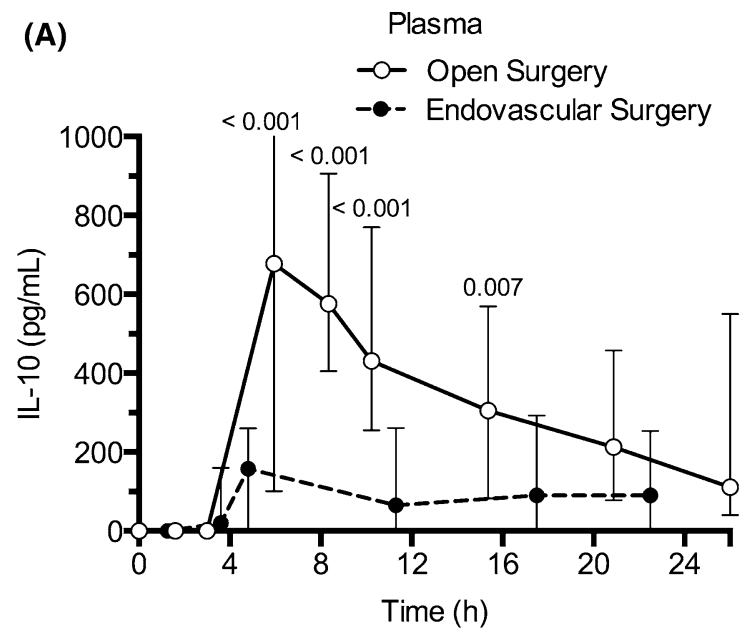

Fig. 2 The effect of aortic aneurysm surgery on plasma interleukin10 (IL-10) concentrations. Plasma IL-10 concentrations were determined in patients undergoing open surgical procedures with or without cardiopulmonary bypass or in patients undergoing endovascular surgical procedures (A). The symbols and error bars depict the median [interquartile range (IQR)] raw concentrations $v s$ average sampling times. The $P$ values indicate a significant difference compared with the within-group baseline control value at time 0 , Friedman non-parametric analysis of variance with Bonferroni

group over the first 24-26 hr period (Fig. 3B). The median difference in CSF/plasma albumin ratio between the open and endovascular groups was 13.4 (95\% CI, -1.3 to 43.9$)$.

Assessment of morphine, M3G, and M6G pharmacokinetics

The plasma and CSF concentrations for morphine and M3G stratified by surgical group are shown in Fig. 4. The initial peak median [IQR] concentrations in CSF vs plasma were significantly delayed for morphine $(5.7$ [2.7-7.1] hr $v s$ $1.5[1.1-1.7] \mathrm{hr}$, respectively; $P<0.001)$ and M3G (21.4 [10.6-26.6] hr $\quad$ ss 1.7 [1.3-11.6] hr, respectively; $P<0.001$ ). The shape of the M6G plasma concentration time profile paralleled the M3G profiles, albeit the M6G concentrations were 10-20\% of those measured for M3G (data not shown). Only 15 patients had detectable CSF M6G and typically at later time points. As a result, the CSF M6G measures were not included in further analysis. Since morphine doses differed between patients and the cumulative morphine dose was significantly higher in the open surgical group (Table 1), we determined the dosenormalized AUCs for plasma, CSF morphine, and CSF M3G, which were not different over the 0-6 hr, 0-12 hr, 0$18 \mathrm{hr}$, and 0-24 hr intervals (Table 2). The plasma $\mathrm{M} 3 \mathrm{G} /$ morphine ratio was significantly lower in the open $v s$ endovascular group at 2-6, 6-12, and 12-18 hr after baseline (Table 3). The median [IQR] plasma morphine $t_{1 / 2}$ of elimination was estimated to be significantly longer in
(B)

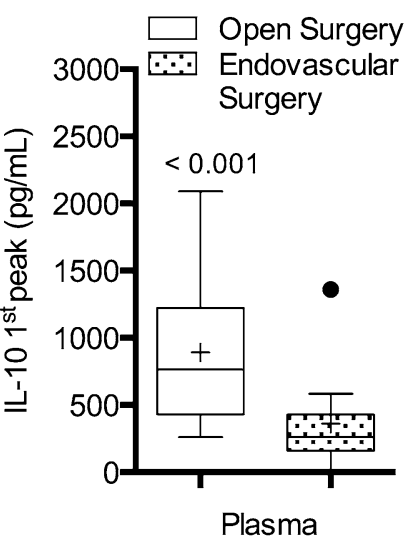

(C)

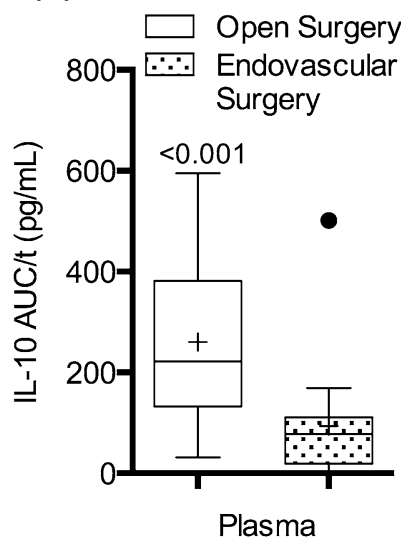

correction for multiple comparisons. Tukey box plots show the median first peak IL-10 concentrations (B) and time-normalized IL10 area under the curves $(C)$ in plasma. Outliers beyond $1.5 \times \mathrm{IQR}$ are identified by the filled circles $(\mathbf{O})$, and the mean values are indicated by the (+) symbol. The $P$ values indicate a significant difference compared with the endovascular surgery group, MannWhitney non-parametric Student's $t$ test. The data analysis in A included samples up to an average time of $26 \mathrm{hr}$ (x-axis) due to limited available samples beyond that time point

the open surgical group (3.7 [2.6-4.8] hr) compared with the endovascular group $(1.6[1.3-2.1] \mathrm{hr})(P<0.001)$. The CSF M3G/morphine ratio did not differ between groups at any of the time intervals. There were insufficient samples to define the terminal elimination half-lives for plasma M3G and M6G and CSF morphine and M3G.

Primary and secondary endpoint analyses

For the primary endpoint analyses, there were no significant correlations between the morphine AUC CSF/plasma ratios and plasma or CSF IL-6 AUC/t. A moderate positive correlation (corrected for age, sex, and the type of surgery) was observed between the M3G AUC CSF/plasma ratio and the CSF IL-6 AUC/t but not the plasma IL-6 AUC/t (Fig. 5). There was no significant correlation between the morphine and M3G AUC CSF/plasma ratios and the plasma IL-10 AUC/t or the $\mathrm{CSF} /$ plasma albumin ratio (data not shown). There were insufficient data on CSF M6G concentration to permit analysis.

For the secondary endpoint analysis, the average or interval (0-2 hr, 2-6 hr, 6-12 hr, 12-18 hr, and 18-24 hr) morphine and M3G AUC CSF/plasma ratios did not differ significantly between the open and endovascular groups (data not shown). The secondary outcome measures were also compared between patients grouped by CPB $(n=17)$ $v s$ non-CPB $(n=16)$. The overall results were similar, likely due to the small number of patients $(n=1)$ 


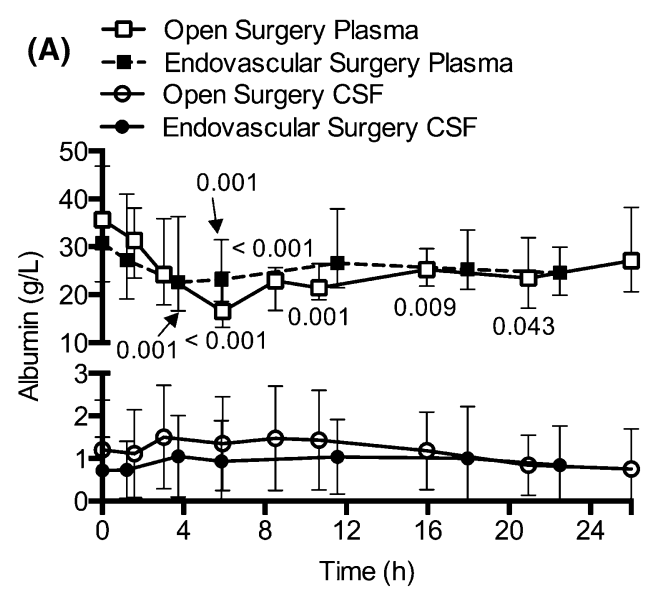

(B)

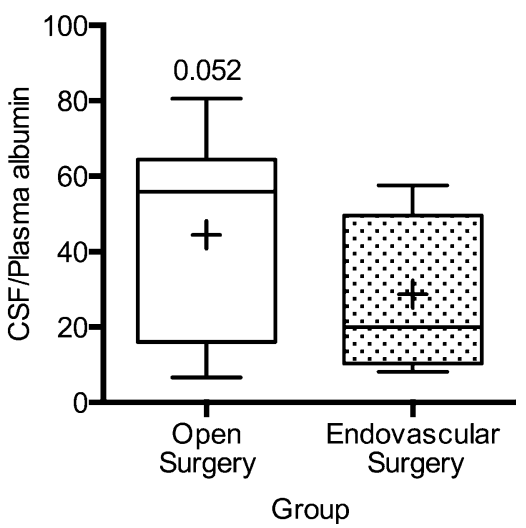

Fig. 3 The effect of aortic aneurysm surgery on plasma and cerebrospinal fluid (CSF) albumin concentrations. Plasma and CSF albumin concentrations were determined in patients undergoing open surgical procedures with or without cardiopulmonary bypass or in patients undergoing endovascular surgical procedures (A). The symbols and error bars depict median interquartile range concentrations $v s$ average sampling times. The $P$ values indicate a significant difference compared with the within-group baseline control value at time 0 , Friedman non-parametric analysis of variance with Bonferroni correction for multiple comparisons. Tukey box plots show the CSF/plasma albumin ratios over time grouped by surgery type (B). The mean values are indicated by the $(+)$ symbol. The $P$ values indicate a significant difference compared with the endovascular surgery group, Mann-Whitney non-parametric Student's $t$ test. The data analysis in A included samples up to an average time of $26 \mathrm{hr}$ (x-axis) due to limited available samples beyond that time point

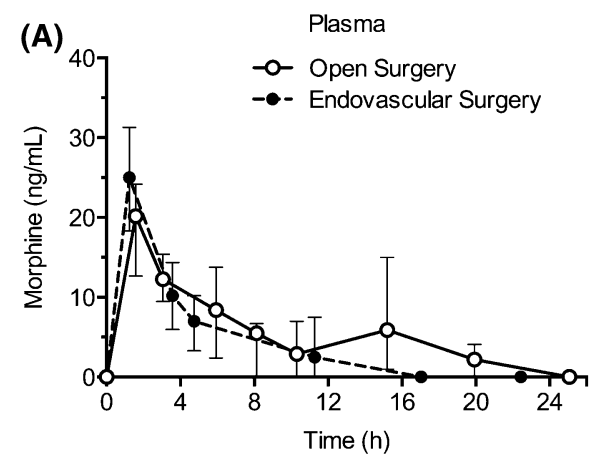

(C)

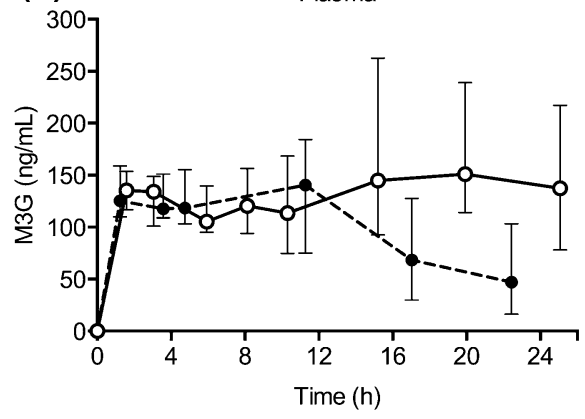

Fig. 4 The effect of aortic aneurysm surgeries on the plasma and cerebrospinal fluid (CSF) concentrations of morphine and morphine3-glucuronide (M3G). Plasma and CSF morphine (A, B) and M3G (C, D) concentrations were measured in patients undergoing open surgical procedures with or without cardiopulmonary bypass or in patients undergoing endovascular surgical procedures. The symbols
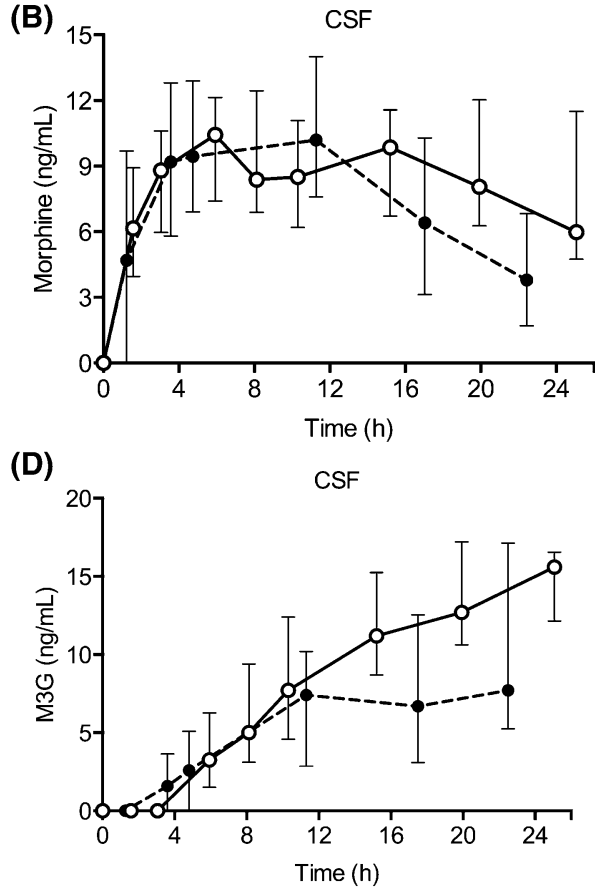

and error bars represent the median interquartile range concentrations $v s$ average sampling times. The clear circles represent patients in the open surgical group and filled circles the patients in the endovascular surgical group. The data analysis included samples up to an average time of $26 \mathrm{hr}$ (x-axis) due to limited available samples beyond that time point 
Table 2 Morphine and M3G plasma and CSF dose-normalized AUCs

\begin{tabular}{|c|c|c|c|c|}
\hline & \multicolumn{4}{|l|}{ Time interval } \\
\hline & $0-6 \mathrm{hr}$ & $0-12 \mathrm{hr}$ & $0-18 \mathrm{hr}$ & $0-24 \mathrm{hr}$ \\
\hline \multicolumn{5}{|l|}{ PL M AUC/D } \\
\hline Endovascular & $6.2[4.2-8.6]$ & $7.7[4.5-13]$ & $6.5[5.4-13]$ & $8.1[5.6-14]$ \\
\hline Open Surgery & $6.6[5.6-7.9]$ & $8.2[5.9-11]$ & $9.9[7.2-11]$ & $9.9[7.2-12]$ \\
\hline$P$ value & 0.81 & 0.79 & 0.38 & 0.72 \\
\hline Median difference $^{\mathrm{a}}$ and $(95 \% \mathrm{CI})$ & $0.07(-2.3$ to 2.3$)$ & $0.67(-4.3$ to 4.3$)$ & $2.1(-2.5$ to 4.6$)$ & $1.1(-3.7$ to 4.9$)$ \\
\hline \multicolumn{5}{|l|}{ CSF M AUC/D } \\
\hline Endovascular & $4.2[3.1-6.1]$ & $7.9[5.8-11]$ & $11[7.8-16]$ & $11[9.2-20]$ \\
\hline Open Surgery & $4.9[2.5-6.1]$ & $7.7[5.5-12]$ & $8.5[6.5-13]$ & $11[6.9-15]$ \\
\hline$P$ value & 0.67 & 0.99 & 0.32 & 0.42 \\
\hline Median difference and $(95 \% \mathrm{CI})$ & $0.38(-1.2$ to 1.8$)$ & -0.05 ( -2.9 to 3.0$)$ & $-1.8(-5.7$ to 1.5$)$ & $-2.0(-7.6$ to 2.7$)$ \\
\hline \multicolumn{5}{|l|}{ PL M3G AUC/D } \\
\hline Endovascular & $78[35-87]$ & $130[110-150]$ & $150[120-180]$ & $170[110-220]$ \\
\hline Open Surgery & $69[62-85]$ & $120[110-140]$ & $160[110-190]$ & $210[140-250]$ \\
\hline$P$ value & 0.67 & 0.60 & 0.79 & 0.27 \\
\hline Median difference and $(95 \% \mathrm{CI})$ & $3.1(-14$ to 18$)$ & $-8.2(-32$ to 29$)$ & $4.9(-41$ to 48$)$ & $29(-28$ to 89$)$ \\
\hline \multicolumn{5}{|l|}{ CSF M3G AUC/D } \\
\hline Endovascular & $0.9[0.4-1.0]$ & $3.3[2.3-3.8]$ & $6.4[5.3-9.1]$ & $9[4.8-14]$ \\
\hline Open Surgery & $0.9[0.4-1.4]$ & $3.4[2.4-4.4]$ & $6.0[4.8-8.6]$ & $10[7.5-13]$ \\
\hline$P$ value & 0.80 & 0.99 & 0.63 & 0.74 \\
\hline Median difference and 95\% CI & $0.06(-0.48$ to 0.59$)$ & $0.03(-0.99$ to 2.4$)$ & $-0.47(-2.9$ to 3.4$)$ & $0.93(-4.2$ to 5.6$)$ \\
\hline
\end{tabular}

The AUC/D values are shown as median [interquartile range]. The units for AUC/D are $\mathrm{mL} \cdot \mathrm{hr}^{-1} \times 10^{-6}$. ${ }^{\text {a }}$ The reported median difference is the Hodges-Lehman difference in the medians of the open $v s$ endovascular groups. The corresponding $95 \%$ confidence intervals (CIs) of the median differences are shown in brackets. AUC = area under the curve; $\mathrm{CSF}=$ cerebrospinal fluid; $\mathrm{D}=$ dose; $\mathrm{M}=$ morphine; $\mathrm{M} 3 \mathrm{G}=$ morphine3-glucuronide; $\mathrm{PL}=$ plasma

Table 3 M3G/morphine ratios in endovascular $v s$ open surgery groups

\begin{tabular}{|c|c|c|c|c|c|}
\hline & \multicolumn{5}{|l|}{ Time Interval } \\
\hline & $0-2 \mathrm{hr}$ & $2-6 \mathrm{hr}$ & $6-12 \mathrm{hr}$ & $12-18 \mathrm{hr}$ & $18-24 \mathrm{hr}$ \\
\hline \multicolumn{6}{|l|}{ Plasma M3G/M } \\
\hline Endovascular & $6.4[5.1-9.8]$ & $17[10-21]$ & $30[25-37]$ & $48[29-120]$ & $11[8.3-83]$ \\
\hline Open Surgery & $6.8[5.3-9.5]$ & $12[8.8-13]$ & $20[13-27]$ & $24[11-41]$ & $38[12-69]$ \\
\hline$P$ value $^{\mathrm{a}}$ & 0.61 & 0.032 & 0.0089 & 0.035 & 0.67 \\
\hline Median difference and $95 \% \mathrm{CI}^{\mathrm{b}}$ & $0.44(-1.8$ to 2.6$)$ & $-4.8(-9.2$ to -0.40$)$ & $-12(-17$ to -2.3$)$ & $-30(-107$ to -0.53$)$ & $4.5(-73$ to 69$)$ \\
\hline \multicolumn{6}{|l|}{ CSF M3G/M } \\
\hline Endovascular & $0.04[0-0.45]$ & $0.25[0.15-0.51]$ & $0.54[0.37-0.91]$ & $0.91[0.63-1.9]$ & $1.6[0.77-3.9]$ \\
\hline Open Surgery & $0.12[0.07-0.87]$ & $0.24[0.15-0.39]$ & $0.72[0.48-0.93]$ & $0.92[0.76-1.5]$ & $1.7[1.4-2.2]$ \\
\hline$P$ value & 0.28 & 0.76 & 0.31 & 0.97 & 0.96 \\
\hline Median difference and $95 \% \mathrm{CI}$ & $0.10(-0.45$ to 0.98$)$ & $-0.02(-0.26$ to 0.16$)$ & $0.18(-0.17$ to 0.48$)$ & $-0.01(-0.86$ to 0.55$)$ & $0.04(-1.6$ to 0.97$)$ \\
\hline
\end{tabular}



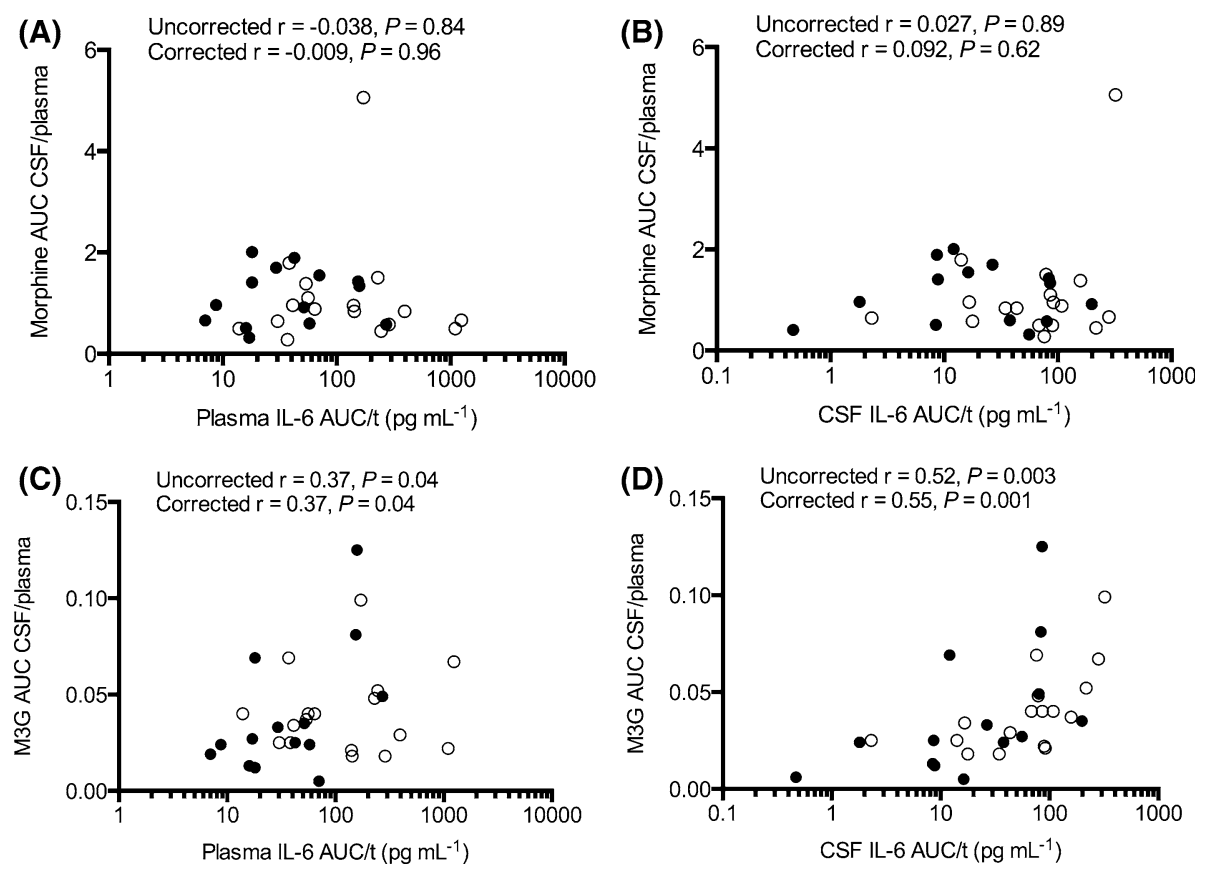

Fig. 5 Weighted between-patient correlations of morphine and morphine-3-glucuronide (M3G) area under the curve (AUC) cerebrospinal fluid (CSF)/plasma ratios with plasma and CSF interleukin (IL)-6 exposure. For each patient, the morphine and M3G AUC CSF/plasma ratios and $\log _{10}$-normalized IL-6 exposures were calculated and weighted for the number of paired measurements in each patient. Pearson's correlations were performed on the

undergoing open thoracotomy without CPB (data not shown). In those patients that underwent open surgery with $\mathrm{CPB}$, plasma IL-6 and IL-10 rose sharply from the pre-CPB to the post-CPB time points, suggesting that the $\mathrm{CPB}$ procedure and heparin administration could be contributing to the observed increase in cytokine levels (data not shown).

\section{Discussion}

Our results suggest that BBB PGP activity and CSF distribution of morphine were not altered by the systemic inflammatory response or by the less robust CNS inflammatory response. These results are consistent with our previous study, which also failed to show an impact of acquired brain injury on the CSF distribution of morphine. ${ }^{2}$ The secondary endpoint analyses revealed a more robust systemic inflammatory response in the open $v s$ endovascular group. Nevertheless, this differential inflammatory response was not associated with a significant difference in the CSF/plasma morphine AUC ratio in the open $v s$ endovascular surgical groups, arguing against a surgery-specific effect of PGP on BBB morphine efflux transporter function. This result is consistent with

weighted mean values. The uncorrected and corrected (for age, sex, and surgery) correlations and corresponding $P$ values are provided in each figure. The clear circles represent patients in the open surgical group and filled circles represent the patients in the endovascular surgical group. A Bonferroni corrected $P<0.017$ indicated a significant correlation

observations in a rat model, which showed no change in PGP expression $24 \mathrm{hr}$ following CPB and deep hypothermic circulatory arrest. ${ }^{31}$ The clinical implications of this finding are that, in humans, the penetration of morphine into the CNS will be unaltered by inflammation occurring over the first $24 \mathrm{hr}$ postoperatively.

We chose to conduct our study in patients undergoing open $v s$ endovascular elective aortic surgical repair because these procedures produce a systemic inflammatory response characterized by elevated concentrations of proinflammatory cytokines proportional to the extent of surgical trauma. Further, the cytokines liberated during this response have previously been linked to inflammationmediated changes in BBB drug efflux transporters. ${ }^{4,32-34}$ Systemic inflammation was evident in this study by increased plasma concentrations of the pro-inflammatory IL-6 and anti-inflammatory IL-10 cytokines and by decreased plasma albumin, a negative acute phase reactant. The observation of a lesser, yet significant, increase in CSF IL-6 is consistent with the known occurrence of the peripheral-brain humoral immune transmission process and subsequent CNS inflammatory response. $^{35,36}$

The median plasma $t_{1 / 2} \mathrm{~s}$ of morphine were in the expected range. ${ }^{37}$ Nevertheless, the prolonged morphine 
half-life and reduction in plasma $\mathrm{M} 3 \mathrm{G} /$ morphine ratios in the open surgical group suggested that reduced morphine metabolism occurred following surgery. This could be the result of inflammation-mediated reductions in the function of hepatic UDP-glucuronosyltransferase $2 \mathrm{~B} 7$, the primary enzyme responsible for morphine metabolism to $\mathrm{M} 3 \mathrm{G}$ in humans. $^{38,39}$ Although the reduction in morphine metabolism to $\mathrm{M} 3 \mathrm{G}$ may have also occurred in the human brain, ${ }^{40}$ the CSF M3G/morphine ratio was similar in the open $v s$ endovascular groups, arguing against an altered central metabolism as the cause.

The possibility that increased brain distribution of $\mathrm{M} 3 \mathrm{G}$ follows the systemic inflammatory response produced by aortic surgery is not supported by our primary outcome analyses. Nevertheless, the M3G AUC CSF/plasma ratio correlated with CSF IL-6 AUC/t, indicating that an alteration in BBB M3G pharmacokinetics may occur due to the CNS inflammatory response. Supporting this, the correlation between the CSF/plasma AUC ratios for $\mathrm{M} 3 \mathrm{G}$ was similar in magnitude in the present study to that observed in our previous study of the CNS inflammatory response produced by acquired brain injury. ${ }^{2}$ The magnitude of the inflammatory response in the CNS following vascular surgery was substantially lower (based on average CSF IL6 exposure) than the previous study, suggesting that an alteration in the brain distribution of $\mathrm{M} 3 \mathrm{G}$ occurs over a broad range of inflammatory responses. While the exact mechanisms cannot be deduced, downregulation of MRP and/or solute carrier organic anion transporters by elevated CSF IL-6 and reduced efflux transport of M3G could be contributing factors. ${ }^{2,4,41,42}$ Supporting this, the CSF IL-6 concentrations observed in our study were at the lower end of the range $\left(300-20,000 \mathrm{pg} \cdot \mathrm{mL}^{-1}\right)$ that significantly alters the expression and/or function of various $\mathrm{ABC}$ transporters in cell culture models. ${ }^{20,21,43,44}$ Furthermore, the observation that $\mathrm{M} 3 \mathrm{G}$ concentration continues to increase in the CSF despite stable or falling plasma concentrations could in part reflect inflammation-mediated reduction in BBB drug efflux transporter function with time. The clinical implications of this finding are that, in man, the penetration of $\mathrm{M} 3 \mathrm{G}$ into the CNS is enhanced by the inflammatory response occurring during surgery and may be manifest as altered CNS disturbances, including agitation, as has been observed in animal models. ${ }^{45}$ This observation requires further investigation and validation. No such disturbances were observed in any of the patients enrolled in this study.

We observed a decline in plasma albumin, a result that was consistent with either hemodilution or capillary leak caused by the surgery-induced inflammatory response. ${ }^{46}$ We also inferred from the increased CSF/plasma albumin ratio that $\mathrm{BBB}$ passive permeability increased in the immediate postoperative period to a greater degree in patients undergoing open surgical procedures. The sensitivity of albumin CSF/plasma ratios as a marker of passive BBB permeability may be questioned. Nevertheless, other human studies in similar patient populations have employed this ratio for the same purpose, ${ }^{28,46}$ and given the observational and preliminary investigative nature of the study, it was not considered practical or feasible to utilize other investigative methods such as radioisotopes or functional MRI. The lack of correlation between the morphine and $\mathrm{M} 3 \mathrm{G} \mathrm{CSF} /$ plasma AUC ratios and the CSF/albumin ratio suggests that a change in BBB passive permeability did not influence the primary or secondary study outcome measures for morphine or $\mathrm{M} 3 \mathrm{G}$.

Comparing our results with published data by Meineke et $a l .{ }^{10}$ reveals a time delay in the attainment of peak morphine and $\mathrm{M} 3 \mathrm{G}$ concentration in the lumbar CSF relative to the ventricular CSF following intravenous morphine administration. The degree to which this time-shifted hysteresis between ventricular/lumbar CSF morphine and $\mathrm{M} 3 \mathrm{G}$ concentrations alters the interpretation of our results is unknown, and we acknowledge this as a limitation. Nevertheless, since the delayed distribution to the lumbar CSF relative to ventricular CSF was proportional for parent drug and metabolite, the lumbar CSF concentrations of morphine and $\mathrm{M} 3 \mathrm{G}$ should reflect their concentrations in the ventricular CSF and brain parenchyma. Furthermore, the use of time-inclusive AUC ratios should account for and mitigate some of the distribution-related effects and be reflective of alterations (or lack thereof) in BBB transport. Comparable results in our current study vs previous study, ${ }^{2}$ where we sampled from ventricular CSF, support this assertion.

Our study has several additional limitations. There were insufficient measurable concentrations of M6G in CSF to permit any analysis. This is in distinction from our previous study findings involving a CNS insult. We speculate that this may be due to the longer sampling duration (96 hr vs $26 \mathrm{hr}$ ) and a 25-50-fold higher magnitude CNS inflammatory response, as measured by CSF IL- 6 concentrations, in the previous $v s$ the present study. ${ }^{2}$ The correlation results for M3G are modest, and as a result, conclusions must be tempered. Nevertheless, as the findings agree with those of pre-clinical investigations and we were unable to control for all potentially confounding variables (e.g., differing doses of morphine utilized, differing magnitude of the inflammatory response among patients within a study group), we consider the observed signals to be valid and therefore clinically important. We measured total and not free morphine. Nevertheless, given low plasma protein binding of morphine $(34-38 \%),{ }^{47}$ we expect that the observed reduction in plasma albumin would not significantly impact morphine BBB pharmacokinetics. Potential contributions of functional PGP polymorphisms ${ }^{48,49}$ and other BBB transporters that are regulated by inflammation 
and have overlapping substrate specificity with $\mathrm{PGP}^{20,50}$ could have confounded our ability to detect a significant association between BBB morphine pharmacokinetics and the surgical inflammatory response. P-glycoprotein is also present in the blood-CSF barrier of the choroid plexus where it functions in opposition to that observed at the BBB (i.e., morphine is moved into the CSF not into the blood) and could confound the results. ${ }^{51}$ This effect was not quantifiable, but we suspect the effect to be minimal given the much larger surface area provided by the BBB capillary system $v$ s that of the choroid plexus. We did not measure brain drug concentrations directly and used the CSF concentration as a surrogate for brain drug concentrations. The degree to which this assumption is correct is unknown in humans under the conditions studied. Some patients showed increases in TNF, IL-1 $\beta$, and IFN $\gamma$, all of which may alter drug transporter function. ${ }^{4}$ Nevertheless, the frequencies of the responses were insufficient to allow us to examine their potential role in our observations. Thus, we cannot exclude that a significant interaction involving these cytokines may have influenced our observations; however, our findings for the magnitude of change in inflammatory markers are consistent with what has been reported in the literature. ${ }^{29,52-54}$ Finally, a potential role of concomitant administration of PGP inhibitors/enhancers could not be investigated due to the low number of patients $(n=9)$ receiving a variety $(n=3)$ of these agents.

In summary, our results suggest that, for patients undergoing thoracic aortic aneurysm surgery, the distribution of the PGP substrate morphine across the BBB into the CNS is unaltered in the presence of inflammation as measured by changes in IL-6 CSF/plasma ratios. This suggests that blood-brain barrier PGP function may not be affected by the perioperative inflammatory response. Clinically, the use of continuous infusions of morphine should not need adjustment in the perioperative period based on the effect of the inflammatory response on BBB function, although other reasons for dose adjustment in patients with inflammation may exist, e.g., altered drug metabolism. The distribution of the metabolite M3G into the CSF was altered, but the results require further investigation to determine the clinical relevance and if other altered BBB drug efflux transporters are involved.

Acknowledgements $\mathrm{We}$ are indebted to the patients for their willingness to participate in this investigation and to the Cardiovascular Intensive Care Unit nurses for their help with data collection and collection of samples.

Conflicts of interest The authors declare they have no conflicts of interest with respect to this work.

Editorial responsibility This submission was handled by Dr. Hilary P. Grocott, Editor-in-Chief, Canadian Journal of Anesthesia.
Author contributions Kerry B. Goralski and Richard I. Hall, the study co-principal investigators, conceived and designed the research. Yan Wang, Kathryn Landry, Mark E. Issa, and Lekha Sleno performed the research and generated experimental data. Lisa C. Julien coordinated the clinical trial and recruited patients. Jeremy Wood was the study surgeon and recruited patients. Yan Wang, Derek J. Roberts, Kathryn Landry, Kerry B. Goralski, and Richard I. Hall analyzed and interpreted the study data. Yan Wang, Derek J. Roberts, Kerry B. Goralski, and Richard I. Hall wrote the manuscript. Kerry B. Goralski supervised the trainees Yan Wang, Kathryn Landry, and Mark E. Issa.

Funding Financial support for this investigation was provided by the Heart and Stroke Foundation of Canada (Nova Scotia Chapter), the Canadian Anesthesiologists' Society, the Canadian Anesthesiologists Research Foundation, and the Dalhousie University Pharmacy Endowment Fund.

\section{References}

1. Roberts DJ, Hall RI. Drug absorption, distribution, metabolism and excretion considerations in critically ill adults. Expert Opin Drug Metab Toxicol 2013; 9: 1067-84.

2. Roberts DJ, Goralski KB, Renton $K W$, et al. Effect of acute inflammatory brain injury on accumulation of morphine and morphine 3- and 6-glucuronide in the human brain. Crit Care Med 2009; 37: 2767-74.

3. Skrobik Y, Leger C, Cossette M, Michaud V, Turgeon J. Factors predisposing to coma and delirium: fentanyl and midazolam exposure; CYP3A5, ABCB1, and ABCG2 genetic polymorphisms; and inflammatory factors. Crit Care Med 2013; 41: 999-1008.

4. McNeil JO, Goralski KB. Drug-cytokine interactions. In: Piscitelli SC, Rodvold KA, Pai MP (Eds). Drug Interactions in Infectious Diseases, 3rd Edition. New York, Springer Science and Business Media; 2011.

5. Schinkel AH, Wagenaar E, van Deemter L, Mol CA, Borst P. Absence of the mdrla P-gGlycoprotein in mice affects tissue distribution and pharmacokinetics of dexamethasone, digoxin, and cyclosporin A. J Clin Invest 1995; 96: 1698-705.

6. Wandel C, Kim R, Wood M, Wood A. Interaction of morphine, fentanyl, sufentanil, alfentanil, and loperamide with the efflux drug transporter P-glycoprotein. Anesthesiology 2002; 96: 91320.

7. King $M, S u W$, Chang A, Zuckerman A, Pasternak $G W$. Transport of opioids from the brain to the periphery by P-glycoprotein: peripheral actions of central drugs. Nat Neurosci 2001; 4: 268-74.

8. Thompson SJ, Koszdin K, Bernards CM. Opiate-induced analgesia is increased and prolonged in mice lacking $\mathrm{P}$ glycoprotein. Anesthesiology 2000; 92: 1392-9.

9. Letrent SP, Pollack GM, Brouwer KR, Brouwer KL. Effects of a potent and specific P-glycoprotein inhibitor on the blood-brain barrier distribution and antinociceptive effect of morphine in the rat. Drug Metab Dispos 1999; 27: 827-34.

10. Meineke I, Freudenthaler S, Hofmann U, et al. Pharmacokinetic modelling of morphine, morphine-3-glucuronide and morphine6-glucuronide in plasma and cerebrospinal fluid of neurosurgical patients after short-term infusion of morphine. $\mathrm{Br} \mathrm{J}$ Clin Pharmacol 2002; 54: 592-603.

11. Meissner K, Avram MJ, Yermolenka V, Francis AM, Blood J, Kharasch ED. Cyclosporine-inhibitable blood-brain barrier drug 
transport influences clinical morphine pharmacodynamics. Anesthesiology 2013; 119: 941-53.

12. Sadhasivam $S$, Chidambaran $V$, Zhang $X$, et al. Opioid-induced respiratory depression: ABCB1 transporter pharmacogenetics. Pharmacogenomics J 2015; 15: 119-26.

13. Milne $R W$, Nation RL, Somogyi AA. The disposition of morphine and its 3- and 6-glucuronide metabolites in humans and animals, and the importance of the metabolites to the pharmacological effects of morphine. Drug Metab Rev 1996; 28: 345-472.

14. Klimas R, Mikus G. Morphine-6-glucuronide is responsible for the analgesic effect after morphine administration: a quantitative review of morphine, morphine-6-glucuronide, and morphine-3glucuronide. Br J Anaesth 2014; 113: 935-44.

15. Smith MT. Neuroexcitatory effects of morphine and hydromorphone: evidence implicating the 3-glucuronide metabolites. Clin Exp Pharmacol Physiol 2000; 27: 524-8.

16. Miller DS. Regulation of $\mathrm{ABC}$ transporters blood-brain barrier: the good, the bad, and the ugly. Adv Cancer Res 2015; 125: 4370 .

17. van de Wetering $K$, Zelcer $N$, Kuil A, et al. Multidrug resistance proteins 2 and 3 provide alternative routes for hepatic excretion of morphine-glucuronides. Mol Pharmacol 2007; 72: 387-94.

18. Roberts DJ, Goralski KB. A critical overview of the influence of inflammation and infection on P-glycoprotein expression and activity in the brain. Expert Opin Drug Metab Toxicol 2008; 4: 1245-64.

19. Bauer B, Hartz AM, Miller DS. Tumor necrosis factor alpha and endothelin-1 increase P-glycoprotein expression and transport activity at the blood-brain barrier. Mol Pharmacol 2007; 71: 667-75.

20. Poller B, Drewe J, Krahenbuhl S, Huwyler J, Gutmann H. Regulation of BCRP (ABCG2) and P-glycoprotein (ABCB1) by cytokines in a model of the human blood-brain barrier. Cell Mol Neurobiol 2010; 30: 63-70.

21. Ronaldson PT, Bendayan R. HIV-1 viral envelope glycoprotein gp120 triggers an inflammatory response in cultured rat astrocytes and regulates the functional expression of P-glycoprotein. Mol Pharmacol 2006; 70: 1087-98.

22. $Y u$ C, Kastin AJ, Tu H, Waters $S$, Pan W. TNF activates P-glycoprotein in cerebral microvascular endothelial cells. Cell Physiol Biochem 2007; 20: 853-8.

23. Ronaldson PT, Ashraf T, Bendayan R. Regulation of multidrug resistance protein 1 by tumor necrosis factor alpha in cultured glial cells: involvement of nuclear factor-kappaB and c-Jun Nterminal kinase signaling pathways. Mol Pharmacol 2010; 77: 644-59.

24. Seelbach MJ, Brooks TA, Egleton RD, Davis TP. Peripheral inflammatory hyperalgesia modulates morphine delivery to the brain: a role for P-glycoprotein. J Neurochem 2007; 102: 167790.

25. Syvanen $S$, Lindhe $O$, Palner $M$, et al. Species differences in blood-brain barrier transport of three positron emission tomography radioligands with emphasis on $\mathrm{P}$-glycoprotein transport. Drug Metab Dispos 2009; 37: 635-43.

26. Hatherell K, Couraud PO, Romero IA, Weksler B, Pilkington GJ. Development of a three-dimensional, all-human in vitro model of the blood-brain barrier using mono-, co-, and tri-cultivation Transwell models. J Neurosci Methods 2011; 199: 223-9.

27. von Elm E, Altman DG, Egger M, et al. The Strengthening the Reporting of Observational Studies in Epidemiology (STROBE) statement: guidelines for reporting observational studies. Epidemiology 2007; 18: 800-4.

28. Reinsfelt B, Ricksten SE, Zetterberg H, Blennow K, FredenLindqvist $J$, Westerlind A. Cerebrospinal fluid markers of brain injury, inflammation, and blood-brain barrier dysfunction in cardiac surgery. Ann Thorac Surg 2012; 94: 549-55.
29. Hall $R$. Identification of inflammatory mediators and their modulation by strategies for the management of the systemic inflammatory response during cardiac surgery. J Cardiothorac Vasc Anesth 2013; 27: 983-1033.

30. Bland JM, Altman DG. Correlation, regression, and repeated data. BMJ 1994; 308: 896.

31. Bartels $K$, Ma Q, Venkatraman $T N$, et al. Effects of deep hypothermic circulatory arrest on the blood brain barrier in a cardiopulmonary bypass model-a pilot study. Heart Lung Circ 2014; 23: 981-4.

32. Hall RI, Smith MS, Rocker G. The systemic inflammatory response to cardiopulmonary bypass: pathophysiological, therapeutic, and pharmacological considerations. Anesth Analg 1997; 85: 766-82.

33. Moris DN, Kontos MI, Mantonakis EI, et al. Concept of the aortic aneurysm repair-related surgical stress: a review of the literature. Int J Clin Exp Med 2014; 7: 2402-12.

34. Akowuah E, Wilde P, Angelini G, Bryan AJ. Systemic inflammatory response after endoluminal stenting of the descending thoracic aorta. Interact Cardiovasc Thorac Surg 2007; 6: 741-3.

35. Dantzer R, O'Connor JC, Freund GG, Johnson RW, Kelley KW. From inflammation to sickness and depression: when the immune system subjugates the brain. Nat Rev Neurosci 2008; 9: 46-56.

36. Sankowski R, Mader S, Valdes-Ferrer SI. Systemic inflammation and the brain: novel roles of genetic, molecular, and environmental cues as drivers of neurodegeneration. Front Cell Neurosci 2015; 9: 28.

37. Lugo RA, Kern SE. Clinical pharmacokinetics of morphine. J Pain Palliat Care Pharmacother 2002; 16: 5-18.

38. Chau N, Elliot DJ, Lewis BC, et al. Morphine glucuronidation and glucosidation represent complementary metabolic pathways that are both catalyzed by UDP-glucuronosyltransferase 2B7: kinetic, inhibition, and molecular modeling studies. J Pharmacol Exp Ther 2014; 349: 126-37.

39. Congiu M, Mashford ML, Slavin JL, Desmond PV. UDP glucuronosyltransferase mRNA levels in human liver disease. Drug Metab Dispos 2002; 30: 129-34.

40. Sandouk P, Serrie A, Scherrmann JM, Langlade A, Bourre JM. Presence of morphine metabolites in human cerebrospinal fluid after intracerebroventricular administration of morphine. Eur $\mathbf{J}$ Drug Metab Pharmacokinet 1991; Spec No 3: 166-71.

41. Gibson CJ, Hossain MM, Richardson JR, Aleksunes LM. Inflammatory regulation of ATP binding cassette efflux transporter expression and function in microglia. J Pharmacol Exp Ther 2012; 343: 650-60.

42. Sukhai M, Yong A, Kalitsky J, Piquette-Miller M. Inflammation and interleukin- 6 mediate reductions in the hepatic expression and transcription of the mdr1a and mdr1b Genes. Mol Cell Biol Res Commun 2000; 4: 248-56.

43. Dreuw A, Hermanns HM, Heise $R$, et al. Interleukin-6-type cytokines upregulate expression of multidrug resistanceassociated proteins in NHEK and dermal fibroblasts. J Invest Dermatol 2005; 124: 28-37.

44. Lee G, Piquette-Miller M. Influence of IL-6 on MDR and MRPmediated multidrug resistance in human hepatoma cells. Can J Physiol Pharmacol 2001; 79: 876-84.

45. Skarke C, Geisslinger G, Lotsch J. Is morphine-3-glucuronide of therapeutic relevance? Pain 2005; 116: 177-80.

46. Hubner M, Mantziari S, Demartines $N$, Pralong F, Coti-Bertrand $P$, Schafer $M$. Postoperative albumin drop is a marker for surgical stress and a predictor for clinical outcome: a pilot study. Gastroenterol Res Pract 2016; 2016: 8743187.

47. Olsen GD. Morphine binding to human plasma proteins. Clin Pharmacol Ther 1975; 17: 31-5. 
48. Campa D, Gioia A, Tomei A, Poli P, Barale R. Association of $\mathrm{ABCB} 1 / \mathrm{MDR} 1$ and OPRM1 gene polymorphisms with morphine pain relief. Clin Pharmacol Ther 2008; 83: 559-66.

49. Marzolini C, Paus E, Buclin T, Kim RB. Polymorphisms in human MDR1 (P-glycoprotein): recent advances and clinical relevance. Clin Pharmacol Ther 2004; 75: 13-33.

50. Begley DJ. ABC transporters and the blood-brain barrier. Curr Pharm Des 2004; 10: 1295-312.

51. Graff CL, Pollack GM. Drug transport at the blood-brain barrier and the choroid plexus. Curr Drug Metab 2004; 5: 95-108.

52. Franke $A$, Lante $W$, Fackeldey $V$, et al. Pro-inflammatory cytokines after different kinds of cardio-thoracic surgical procedures: is what we see what we know? Eur J Cardiothorac Surg 2005; 28: 569-75.

53. Franke A, Lante W, Fackeldey V, et al. Proinflammatory and antiinflammatory cytokines after cardiac operation: different cellular sources at different times. Ann Thorac Surg 2002; 74: 363-70; discussion 370-1.

54. Teoh KH, Bradley CA, Gauldie J, Burrows H. Steroid inhibition of cytokine-mediated vasodilation after warm heart surgery. Circulation 1995; 92: II347-53. 